\title{
Consumer rights of the elderly as vulnerable consumers in South Africa: some comparative aspects of the Consumer Protection Act 68 of 2008
}

\author{
Jacolien Barnard \\ Faculty of Law, University of Pretoria, Pretoria, South Africa
}

\section{Keywords}

Elderly consumers, South Africa, vulnerable consumers, consumer protection, consumer rights, equality, commercial practices.

\begin{abstract}
Although consumer protection is not a new concept in South African law, the Consumer Protection Act 68 of 2008 (CPA) now provides for a much more comprehensive and encompassing mechanism to protect consumers. Consumers are protected, not only in the provision of goods and services, the conclusion of contracts but also in the promotion and marketing thereof. The CPA further provides special protection to a particular type of consumer which is the vulnerable consumer and includes elderly consumers. Importantly, and for the first time in the history of South African law, the consumer is provided with eight core fundamental consumer rights. As this contribution is an attempt to provide an interdisciplinary analysis from a legal perspective, identification of what is considered to be an "elderly" consumer, needs to be assessed by referring to relevant empirical studies from both an international- as well as South African perspective. The focus of this study is on the protection of the elderly as a category of vulnerable consumers in terms of the CPA. The investigation will attempt to show that the elderly is protected in terms of all eight of the fundamental consumer rights within the CPA. Special reference will be made to two fundamental rights of the consumer in terms of the CPA. Firstly, the elderly consumer's right to equality in the consumer market (Part A of the CPA) which provides additional protection as the CPA also refers to the Constitutional right to equality. Secondly, the elderly consumer's the right to fair and responsible marketing (Part E of the CPA) which in terms of the research is compared to the EU Unfair Commercial Practices Directive. Certain problems regarding elderly consumers are identified and the importance of consumer rights as well as the implementation of the correct consumer policy is argued.
\end{abstract}




\section{Introduction}

The protection of elderly consumers is more evident today in an age of consumerism than ever before. The trend of consumerism is occurring throughout the globe including in developing countries such as South Africa. Aging is a privilege and a societal achievement. It is also a challenge, which will have an impact on all aspects of 21 st century society. It is a challenge that cannot be addressed by the public or private sectors in isolation: It requires joint approaches and strategies (Sahin, 2008).

Although consumer protection is not a new concept in South African law, the Consumer Protection Act 68 of 2008 (CPA) now provides for a much more comprehensive and encompassing mechanism to protect consumers. Consumers are protected, not only in the provision of goods and services, the conclusion of contracts but also in the promotion and marketing thereof. The CPA further provides (from the outset as part of the preamble to the Act) special protection to a particular type of consumer which is the vulnerable consumer. In terms of section 3 of the CPA the vulnerable consumer includes low-income, illiterate, young and elderly consumers. Importantly, and for the first time in the history of South African law, the consumer is provided with eight core fundamental consumer rights. As this contribution is an attempt to provide an interdisciplinary analysis from a legal perspective, identification of what is considered to be an "elderly" consumer, needs to be assessed by referring to relevant empirical studies from both an international as well as South African perspective. The focus of this study is on the protection of the elderly as a category of vulnerable consumers in terms of the CPA. The investigation will attempt to show that the elderly is protected in terms of all eight of the fundamental consumer rights within the CPA. The eight types of fundamental rights provided to consumers (and in the case of this investigation the elderly consumer in particular) in terms of the CPA are (a) the right to equality in the consumer market; (b) the right to privacy; (c) the consumer's right to choose; (d) the right to disclosure and information; (e) the right to fair and responsible marketing; (f) the right to fair and honest dealing; (g) the right to just, fair and reasonable terms and conditions; and (g) the right to fair value, good quality and safety. Special reference will be made to two fundamental rights of the consumer in terms of the CPA. Firstly, the elderly consumer's right to equality in the consumer market (Part A of the CPA) which provides additional protection as Part A also refers to the Constitutional right to equality. Secondly, the elderly consumer's the right to fair and responsible marketing (Part E of the CPA) will be investigated which, in terms of the study is compared to the EU Unfair Commercial Practices Directive (2005/29) (UCPD). Certain problems with regard to the elderly as consumers are identified and the importance of consumer's rights as well as the implementation of the correct consumer policy is argued.

\section{The elderly as consumers}

Who may be regarded as an "elderly consumer"? The age from which studies on the elderly as consumers are done vary greatly. The group referred to as "elderly consumers" contains very old consumers (e.g., 90+) but also 'younger' elderly consumers (e.g., 65 year-old) (Duivenvoorde, 2013; Lyon and
Bayliss, 1987). Klemz et al. (2010) refers to persons from the age of 50 to 93 while the UN Department of Economic and Social Affairs (2011) refers to persons of 60 years or older. The study done by the UNECE (2009) includes persons of 65 years and older. Perhaps it is also important to take note of the population projections of older persons in for example Europe. The 2008-based national population projections convergence scenario (2008) shows the EU27 population is projected to become older with the median age projected to rise from 40.4 years in 2008 to 47.9 years in 2060 . The share of people aged 65 years or over in the total population is projected to increase from $17.1 \%$ to $30.0 \%$ and the number is projected to rise from 84.6 million in 2008 to 151.5 million in 2060. Similarly, the number of people aged 80 years or over is projected to almost triple from 21.8 million in 2008 to 61.4 million in 2060 .

There is no official retirement age in South Africa and the age of an "elderly", "old person" or "senior person" will depend on the particular relevant legislation. In terms of the Older Persons Act (13/2006) for example "older person" means a male of 65 years and older or a female of 60 years and older (Van Eeden, 2013). The meaning of "retired persons" in terms of the Housing Development Schemes for Retired Persons Act $(65 / 1988)$ means both males and females older than 50 years whereas the Social assistance Act (13/2004) provides that only persons older than 60 qualify for an older person's grant. Although "elderly" is not defined in terms of the CPA the consumer's right to equality in the consumer market refers in particular to adults who have attained a specified age of at least 60 years (s 9). For purposes of this investigation therefore, elderly consumers are regarded as persons of the age of 60 years or older to which goods or services are supplied in the ordinary course of the suppliers business for consideration ( $\mathrm{s}$ $1)$.

In terms of consumer behaviour in the consumer market elderly consumers are often referred to as an "emerging market" (Klemz et al., 2010) or the "mature market" (Beneke et al., 2011). Many arguments have been made that not only are elderly consumers a market segment that has been underutilised (Potgieter et al., 2013; Num et al., 2007) or underrecognised (Klemz et al., 2010) but the protection of this type of consumer is of paramount importance. Historically older consumers have been unattractive to marketers (Omar et al., 2014). Potgieter et al. (2013) explain that generation theorists propose that as the macro-environment changes; there are concomitant and distinct changes in the patterns of consumer behaviour in different age groupings (also referring to Strauss and Howe, 1997). Meneely et al. (2008) show that demographic changes occurring in developed countries has meant that older consumers are becoming an increasingly important consumer segment that retailers need to pay particular attention to. It is essential that their specific needs within the food and other service sectors are met.

Bakewell and Mitchell (2003) propose that younger consumers are more likely to develop different shopping styles to older generations. It was found that younger females tend to be more recreational shoppers, as well as more easily confused by over-choice than older females. There are significant differences in the mean levels of consumer decision-making styles across the factors of the CSI for different age groups (Bakewell and Mitchell, 2003).

Hervé and Mullet (2009) examined the processes involved in consumer judgements among participants of different ages. The first research question was whether the three factors already 
shown as operative by Troutman and Shanteau (1976), namely, price, durability and suitability, would be given the same weight by people of different age groups (18-25, 35-50, 65-74 and 75 years and over). Results indicated that elderly people (65-90 years old) focused on durability. This could be because of the pressure of retirement and family obligations felt by people of this age group and that their greatest concern was the durability of the goods (Hervé and Mullet, 2009).

The needs and desires of young and old people differ due to their living environment and habits. Hence their respective consumer behaviour and expenses are different as well (Rousseau \& Du Plessis, 2003). An ageing population is faced with a changing consumption structure compared to a population with stable age distribution (Stöver, 2013). It is now necessary to analyse the elderly consumer as a vulnerable consumer in the consumer market and the protection of the elderly in this regard.

\section{Elderly consumers as vulnerable consumers in South Africa and the Consumer Protection Act}

Globally studies have been made regarding the vulnerability of consumers and why elderly consumers are considered to be vulnerable which include the consumer behaviour of the elderly (Duivenvoorde, 2013; Yoon and Cole, 2008). The elderly are considered vulnerable due to for example declining decision-making skills and social isolation. For example in Europe, it is argued by Duivenvoorde (2013) not all elderly consumers should be considered to be automatically vulnerable just because of their age. When considering the use of something technologically advanced such as the internet, it is argued by Eastman and Iyer (2005) that policy makers interested in increasing the participation of seniors, can utilize the Internet to reach those who are younger in terms of cognitive age. In the financial sector, the policy to allow banks and lenders to 'pre-screen' potential customers will exacerbate personal debt levels, rather than reducing them and can also lead to the inaccurate assessment of elderly consumers as being vulnerable when they are not or vice versa (Harrisson \& Gray, 2010). The absence or presence of vulnerability in elderly consumers may also be determined from a typographical perspective as Kolodinsky (2001) argues that there is a difference between urban and rural elderly consumers and what they regard as consumer satisfaction. In countries such as Malaysia attempts have been made to assess regional differences (between West and East Malaysia) in the well-being of the elderly as indicated by the income inequality and the influence this has on the elderly's vulnerability level (Masud \& Haron, 2008).

South Africa on the other hand should be regarded as a developing country with continued "third-world" problems including the vulnerability of elderly consumers. This is so also due to the historical disadvantages of certain population groups. According to Statistics South Africa (2014) vulnerable groups constitute a significant proportion of the South African population. Children, youth and older persons respectively comprised $36 \%, 37 \%$ and $8 \%$ of the total population in 2012 and 4,01 million people in South Africa were aged 60 years or older representing $7,7 \%$ of the population. More importantly the study (Statistics South Africa, 2014) showed that older persons were increasingly required to play an active care and support role in their respective households.

The CPA is a relatively new piece of legislation in South Africa and was enacted incrementally with the date of full enforcement 30 March 2011. It is an attempt by the legislature to provide a comprehensive consumer protection policy in South Africa. It is also the first time in the history of South Africa that consumers are provided with eight core fundamental rights which, according to the purpose of the Act, must be developed and protected (s 2). It is important to identify that the CPA provides protection throughout the supplier-consumer relationship which include the marketing of the goods and services to the consumer, the actual provision of the goods and services and any goods and services provided as part of an "after service" agreement (s 2, 4 and 5 of the CPA). For the Act to apply, goods and services must to be supplied to the consumer in the ordinary course of the suppliers business and always for consideration such as money or credits (gift vouchers or customer loyalty points as part of a customer loyalty programme) or any other valid form of counter performance (s 1 and 4).

As stated above elderly consumers are not only afforded the eight core fundamental rights in terms of the CPA but also deserve particular protection because they are also regarded as vulnerable consumers. A discussion and analysis of each of these rights and how they would apply to the elderly consumer, warrants a very extensive and detailed investigation. For purposes of this research therefore, only two important areas will be highlighted: The right to equality in the consumer market and the right to fair and honest dealing.

\section{Elderly consumer's right to equality}

Section 8 of the CPA governs protection against discriminatory marketing. It provides that a supplier of goods or services must not unfairly exclude any person or category of persons from accessing any goods or services offered by the supplier; grant any person or category of persons exclusive access to any goods or services offered by the supplier; assign priority of supply of any goods or services offered by the supplier to any person or category of persons; supply a different quality of goods or services to any person or category of persons; and charge different prices for any goods or services to any persons or category of persons. It further provides that a supplier may not unfairly target particular communities, districts, populations or market segments (such as elderly consumers) for exclusive, priority or preferential supply of any goods or services in a way that amounts to unfair discrimination. Due to the historical and political exclusion of population groups in South Africa the consumer's right to equality is re-enforced by referring to the provisions of the Constitution as well as the Equality Act (4/2000). The CPA provides that the consumer may not be unfairly discriminated against on the basis of one or more grounds of unfair discrimination contemplated in section 9 of the Constitution or Chapter 2 of the Equality Act which include unfairly discriminating on the basis of age.

On the other hand the elderly's right to equality in the consumer market is further protected in terms of section 9 of the CPA which provides that it does not amount to discriminatory marketing if a supplier reasonably designates any facility or service, permanently or from time to time, for the exclusive use of adults who are at least 60 years old or if goods or services are advertised, or it is agreed to supply such goods or services or they are supplied at a discounted price solely on the basis that the consumer who has attained $a$ 
specific age of at least 60 years. A supplier may for example reasonably designate any facility or service for the exclusive use of persons of 60 years or older. "Facility" in terms of the CPA means "any premises, space or equipment set up to fulfil a particular function, or at, or on which a particular service is available" (s 1). "Service" includes the provision of any education, information, advice or consultation, access to an event or any premises, activity or facility; the transportation of an individual or any goods; access to any electronic communication infrastructure; the use of any premises or other property in terms of a rental; and a right of occupancy of immovable property. Taking the abovementioned definitions into account relevant examples in practice are the exclusive use of transport (like a bus or taxi service) by older persons to and from a medical clinic, hospital, shopping mall or church. It could be the exclusive use of or access to a facility for extracurricular activities including sports (for example "bowls") or entertainment (exclusive entrance to legitimate gambling facilities). It could also include the exclusive use or rental of immovable property for example access of older persons to residential facilities and housing development schemes (Van Eeden, 2013). It is common practice for many suppliers to offer what is known as "pensioner's discount" in the supply of services such as movie theatres or vacation accommodation. Where there has been an unfair discrimination of elderly consumers, they may approach the Equality court in addition to the normal civil courts for relief and protection ( $\mathrm{s}$ $10)$.

Interestingly, a study in recent years in Europe done by AGE: The European Older People's Platform (2004) showed older people's experience of discrimination in access to goods, facilities and services which included access to housing, financial services as well as in special offers, marketing and the media. The study found that culture is created and reflected in the media and in the images presented in marketing and public relations activity. For many older people television is an important part of leisure activity and older people are a growing and increasingly important part of the consumer market across Europe. However, the images of older people used in these media tools are rarely positive and the approach of the marketing and public relations industry is generally targeted at other age groups in society. According to AGE (2004) there is no country within the European Community that has any restriction on the use of negative stereotypes of older people in the media. Throughout Europe older people are portrayed negatively as out of touch or moody. In the UK, age sector NGO's recently jointly complained to the television regulators about the negative images of older people used in advertisements to promote the change of telephone service providers. The study argues that the use of age as a limiting factor for access to goods, facilities and services will become increasingly difficult to justify and amounts to unfair discrimination in the consumer market and affects the elderly consumer's right to equality.

\section{Elderly consumer's right to fair and honest dealing}

The elderly consumer's right to fair and honest dealing in terms of the CPA in South Africa can be compared with the protection provided to consumers in terms of the Unfair Commercial Practices Directive 2005/29 (UCPD) in Europe. Section 40 of the CPA prohibits suppliers from unconscionable conduct against consumers while section 41 prevents suppliers from giving false, misleading or deceptive representations regarding goods and services. A supplier or an agent of the supplier must not use physical force against a consumer, coercion, undue influence, pressure, harassment or unfair conduct in connection with the marketing of any goods or services, supply of those goods or services or even in the negotiation, conclusion or enforcement of a consumer agreement (s 40(1)). It is further unconscionable for a supplier to take advantage of the fact that a consumer was substantially unable to protect his or her own interests because of a disability, illiteracy or a similar factor such as age (s 40(2)). In relation to the marketing of goods or services the supplier must not by words or conduct give false, misleading or deceptive representations regarding for example the quality, durability, price or material fact of the goods and services (s 41). Unconscionable conduct (s 40) or false, misleading or deceptive representations ( $\mathrm{s} 41$ ) are considered to be prohibited conduct in terms of section 51 of the CPA and any transaction or agreement or even notice resultant from the above is considered to be void (s 51(3)).

The recent case of Standard Bank of South Africa Limited $v$ Dlamini (2013 (1) SA 219 (KZD)) highlighted the importance of the protection of elderly and vulnerable consumers. A motor vehicle was sold on finance to Mr Dlamini (a functionally illiterate and elderly African male). The repayment plan was not explained to him properly by the representatives of either the bank or the motor dealership and the vehicle ended up having a material defect and could not be used. Upon return of the vehicle due to the defect, the bank attempted to enforce the instalment agreement based on clauses in the agreement that was neither explained to the consumer (Mr Dlamini) nor could be understood by him. The court highlighted the importance of the protection of the vulnerable consumer in terms of the CPA and for bridging the socio-economic inequalities substantively, if for no reason but that sustained inequalities and need lead to unrest and social instability, which are not good for business (par 78).

How is the vulnerable consumer in the case of unfair commercial practices dealt with elsewhere? In the case of Europe, article 5(3) of the UCPD states that commercial practices which are likely to materially distort the economic behaviour only of a clearly identifiable group of consumers who are particularly vulnerable to the practice or the underlying product because of their mental or physical infirmity, age or credulity in a way which the trader could reasonably be expected to foresee, shall be assessed from the perspective of the average member of that group (Recital 19 UCPD). This is without prejudice to the common and legitimate advertising practice of making exaggerated statements or statements which are not meant to be taken literally (commonly known as "puffing"). The UCPD is based on the idea that it is appropriate to protect all types of consumers including consumers whose characteristic make them particularly vulnerable to unfair commercial practices such as elderly consumers. The EU Commission (2009) remark that the reasons (criteria) mentioned by article 5 as the basis to establish the vulnerability of a specific category of consumers is listed indicatively and cover a wide range of situations. The EU Commission further discusses three categories of consumers who may also qualify as vulnerable consumers in certain instances because of the age criterion. Broadly speaking it would be the perspective of an older or younger consumer. Elderly consumers may be more intimidated by for example pressure selling or aggressive door-to-door selling (EU Commission, 2011). The elderly might also be particularly vulnerable to practices connected to 
certain products, such as burglar alarms.

The vulnerable consumer test applies if the practice of the trader affects the economic behaviour of a vulnerable group of consumers "in a way which the trader (supplier or business) could reasonably be expected to foresee". According to the EU Commission (2009) this criterion adds an element of proportionality in assessing the effects of a commercial practice on vulnerable consumers and the professional diligence which reasonably can be expected from a trader. It aims at holding traders responsible only if the negative impact of a commercial practice on a category of vulnerable consumers is foreseeable. The aim of the provision is to capture cases of dishonest market practices (e.g., outright frauds or scams) which reach the majority of consumers, but in reality are devised to exploit the weaknesses of certain specific consumer groups such as the elderly.

Micklitz et al. (2009) explain that the reference in recital 18 of the UCPD to vulnerable groups of consumers has a normative component as it purports to evaluate the particular measure used by the trader. The yardstick of control will also vary. As will be seen below, in some countries (such as the UK for example) fraudulent traders specifically target vulnerable consumers, in particular elderly consumers.

The UCPD was implemented in the UK in terms of the Consumer Protection from Unfair Trading Regulations (CPUT Regulations of 2008) the wording of which is very similar to the Directive itself. Ramsay (2012) poses the question whether one of the core objectives of the Regulations should be the protection of the vulnerable consumer in particular and asks how should this be done? The writer argues that under broader equitable conceptions of substantive fairness one of the objectives might also be protecting the vulnerable and the poor, maintaining integrity in marketing and furthering values of risk-sharing and loss-distribution.

According to Collins (2010) the CPUT Regulations of 2008 should catch a number of unsavoury practices that somehow slipped through the consumer law net or were inadequately deterred by existing provisions. A problem identified in doorstep selling-cases reported in the UK media was traders visiting the homes of elderly and frail consumers and effectively refusing to leave before a contract was signed. In such circumstances, the consumer would have the right to cancel the contract in terms of the CPUT Regulations of 2008. Failure by the trader to inform the consumer of the right to cancel the contract is itself an offence (Collins 2010). The consumer rights of the elderly as vulnerable consumers were also confirmed in the case of Crimea Price v Cheshire East Borough Council [2012] EWHC 2927. The trader (supplier) was accused of misleading- as well as aggressive market practices in terms of the CPUT Regulations of 2008. In this case the trader misled the consumer, an elderly woman over the age of 60 into believing that expensive repairs were required to her home. What was done was demanding payment in cash and taking the consumer in question to her bank using harassment, coercion or undue influence. The court stated (par 8) that such conduct by the trader was obviously a disgraceful action in which the trader prayed on the elderly and vulnerable.

\section{Results and Conclusion}

The results of the investigation above show that elderly consumers form an important part of the consumer market and an understanding of the consumer behaviour of the elderly is paramount. It is also clear that as a developing country, South Africa recognises elderly consumers as vulnerable consumers whose consumer rights need protection through appropriate consumer policy that is provided in terms of the CPA. Two of these rights were identified and discussed being the elderly consumer's right to equality in the consumer market and the right to fair and honest dealing where goods and services are supplied to them by suppliers.

Yoon and Cole (2008) suggest that a better understanding of the changes associated with aging and how they interact with intra-individual and contextual factors will benefit multiple audiences including consumers, public policy makers and marketing managers. If we were to aid older adults to successfully meet the challenges of a rapidly changing and increasingly complex consumer environment, greater insights are needed regarding age differences in consumer behaviour.

Older persons constitute an important and growing consumer group. Their share will rise, they dispose of considerable purchasing power, and they tend to use up accumulated savings in old age (UNECE, 2009). Age composition of households is an important element to take into consideration not only for policymakers and civil society, but also for service providers and producers. The UNECE (2009) state that consumer policy targeting older persons provides an opportunity (a) to eliminate information deficits, (b) to take into account the vulnerability of many older consumers, (c) to improve their status as informed consumers with respect to goods and services markets, (d) to inform older persons of their rights vis-à-vis providers of goods and services, and (e) to enhance their ability to enforce their rights. Since economic integration and participation proceeds, among other ways, through consumption and a desired standard of living, older persons can be recognised as a significant consumer group with shared and specific needs, interests and preferences (UNECE, 2009). Suppliers should consider the potentials of products and services tailored to the needs of older persons. Policymakers may furthermore want to promote mainstreaming ageing in the spheres of production, distribution, advertising and the selling of products and services, given the great benefit for older persons as well as businesses and the overall contribution to the economy and the labour market. Designing products in a more user-friendly and practical manner can enable older persons to cope with difficulties in their daily life. Providing accessible and available services and products can significantly contribute to the aim of an equal social, economic, political, and cultural participation of older persons. Hence, policymakers may want to pursue the goal of mainstreaming ageing across all policy fields, including those with respect to older persons as consumers. Brennan and Coppack (2008) argue that the language of consumer empowerment is gaining prominence in policy and strategy documents at the highest levels internationally. Hare and Brennan (2001) argue, by referring in particular to health service delivery to vulnerable consumer groups (such as the elderly), that accessing the experiences of these more vulnerable groups warrants close attention in the development of both policy and practice.

Broderick et al. (2011) reminds us that failure by suppliers and marketers to adequately accommodate groups that 
experience situational or enduring vulnerability can have severe consequences. Lost sales and damage to a business's reputation, for example, are key penalties a business might face. In extreme cases, and as was shown above, suppliers might also be in violation of discrimination and public accommodation laws (Broderick et al., 2011; Nam et al., 2007).

In conclusion, a uniquely South African scenario concerning the effect of HIV/AIDS on the consumer behaviour of the elderly consumer is relevant and was undertaken by Klemz et al. (2010). Business development in emerging markets, known as the 'base of the pyramid', is not without financial risk, and a key concern in South African communities are the costs associated with HIV/AIDS. Due to the enormous demand for healthcare, the South African government has opted for a home-based care system. Caregivers are mainly older women (over the age of 60 years) and their financial survival is critically important. Klemz et al. (2010) studied coping strategies of the elderly caregiver as a consumer for a patient with HIV/AIDS and the implications thereof for economic development. The study found that as the patient's illness progressed (a) the cultural norm ubuntu (a Nguni word meaning "human kindness" and also recognised by the South African Constitution) led the caregiver to increase spending on the patient and a decreased spending on themselves but that (b) the social pressure of stigma led to a very dramatic drop in direct interpersonal assistance to the patient and an increase in spending on themselves. This is clearly a scenario where consumer policy should play a vital role. In this regard consumer information and education to elderly consumers are also significant (Meneely et al., 2008.; Schuh \& Kitson, 2003). Lyon and Bayliss (1987) state that the elderly have a lot in common and what they often share is a disadvantageous place in societies (referring to the elderly in Brittan).

\section{References}

AGE - The European Older People's Platform (2004) Age Barriers: Older people's experience of discrimination in access to goods, facilities and services (http://bit.ly/13875V accessed on 29/10/2014).

Bakewell, C., \& Mitchell, V.W., (2004) Male consumer decisionmaking styles. The International Review of Retail, Distribution and Consumer Research, 14(2), 223-240.

Beneke, J., Frey, N., Chapman, N., Mashaba, N., \& Howie, T. (2011) The grey awakening: a South African perspective. Journal of Consumer Marketing, 28, 114-124.

Brennan, C., \& Coppack, M., (2008) Consumer empowerment: global context, UK strategies and vulnerable consumers. International Journal of Consumer Studies, 32, 306-313.

Broderick, J.A., Demangeot, C., Ross Adkins, N., \& Ferguson, N.S., et al (2011) Consumer Empowerment in Multicultural Marketplaces: Navigating Multicultural Identities to Reduce Consumer Vulnerability. Journal of Research for Consumers, 19, 113.

Collins, H., (2010) Harmonisation by Example: European Laws against Unfair Commercial Practices. Modern Law Review, 73(1) $89-118$.

UN Department of Economic and Social Affairs, (2011) Current Status of the Social Situation, Well-Being, Participation in Development and Rights of Older Persons Worldwide Department of Economic and Social Affairs. New York, USA (http://bit.ly/1 ve3rQf accessed on $26 / 10 / 2014$ ).

Duivenvoorde, B., (2013) The Protection of Vulnerable Consumers under the Unfair Commercial Practices Directive. Journal of European Consumer and Market Law, 2, 69-79.
Eastmen, J.K, \& Iyer, R,. (2005) The impact of cognitive age on Internet use of the elderly: an introduction to the public policy implications, International Journal of Consumer Studies, 29, 125136.

Editorial., (2002) Over 60 and overlooked: Marketing to the old. The Economist Intelligence Unit, London, 364, 51-52 (http://econ.st/1xY8Axr accessed on 27/10/2014).

European Commission, DG Justice (2011) Study on the application of Directive 2005/29/EC on Unfair Commercial Practices in the EU Part 1 - Synthesis Report (conducted by Civic Consulting) (http://bit.ly/1DZPuMj accessed on 29/10/2014).

European Commission, Europa., SEC (2009) Guidance on the implementation/application of Directive 2005/29/EC on Unfair Commercial Practices, 3 December 2009, SEC 1666, Brussels.

Giannakouris, K., (2008) Ageing Characterises: The Demographic Perspectives of the European Societies. Statistics In Focus (Eurostat, ) 7/2008, 1-13.

Goldsmith, E.B., \& Piscopo, S., (2013) Advances in consumer education: European initiatives. International Journal of Consumer Studies, 31, 52-61.

Harrison, P., \& Gray, C. (2010) The ethical and policy implications of profiling 'vulnerable' customers. International Journal of Consumer Studies, 34, 437-442.

Hare, C., Law, J., \& Brennan, C. (2013) The vulnerable healthcare consumer: an interpretive synthesis of the patient experience literature. International Journal of Consumer Studies, 37, 299-311.

Hervé, C., \& Mullet, E., (2009) Age and factors influencing consumer behaviour. International Journal of Consumer Studies, 33, 302-330.

Klemz, B.R., Boshoff, C. \& Mizibuko, N. (2010) Business development in emerging markets: the impact on the spending behaviour of elderly caregivers of family members with HIV/AIDS South African Journal of Economic and Management Sciences, 13, 464-475.

Kolodinsky, J. (2001) Satisfaction of disabled rural elders and adults with the quality of community-based long-term care services. International Journal of Consumer Studies, 25, 168-179.

Lyon, P., \& Bayliss, R.A., (1987) The elderly consumer: a British comment. Journal of Consumer Studies \& Home Economics, 11 321-331.

Martins, J.H., (2012) Marketing Segmentation of the Consumer Market in South Africa. International Retail and Marketing Review, 8, 6174.

Masud, J., \& Haron, S A., (2008) Income differences among elderly in Malaysia: a regional comparison. International Journal of Consumer Studies, 32, 335-340.

Meneely, J., Burns, A., \& Strugnell, C., (2008) Food retailers' perceptions of older consumers in Northern Ireland. International Journal of Consumer Studies 32, 341-348.

Micklitz, H.W., et al., (2009) Understanding EU Consumer Law. Intersentia, Antwerpen.

Nam, J., Hamlin, R., Gam, H.J., Kang, J.H., Kim, J., Kumphai, P., Starr, C., \& Richards, L., (2007) The fashion-conscious behaviours of mature female consumers. International Journal of Consumer Studies, 31, 102-108.

Omar, M., Tjandra, B., \& Ensor, J., (2014) Retailing to the "greypound": Understanding the food shopping habits and preferences of consumers over 50 in Scotland. Journal of Retailing and Consumer Service, 21, 753-763.

Pieterse, H. (2008) An Evaluation of Mature Consumer Needs in the Banking Sector. MA, University of South Africa.

Potgieter, D. \& Wiese, M. \& Strasheim, A. (2013) Demographic differences in adult consumers' decision-making styles in Tshwane, South Africa. Journal of Family Ecology and Consumer Sciences, 41, 12-32.

Ramsay, I., (2012) Consumer Law and Policy 3rd edn. Oxford \& Portland, Oregon.

Rousseau, G.G., \& Du Plessis, P. J., (2003) Buyer Behaviour: A Multicultural Approach $3^{\text {rd }}$ edn, Oxford University Press, Cape Town, South Africa.

Sahin, A., (2008) Marketing to aging population: are values held by senior American consumers similar to Turkish consumers?

Innovative Marketing 4, 52-63.

Schuh, M., \& Kitson, M. (2003) Adult consumer education across 
Europe - redressing the market or reaching the vulnerable consumer. International Journal of Consumer Studies, 27, 221-225.

Statistics South Africa (2014) The state of the vulnerable in South Africa. The Fieldworker 5, 4-5.

Stöver,B., (2013) The power of elderly consumers- How demographic change affects the economy through private household demand in Germany. Gesellschaft für Wirtschaftliche Strukturforschung $\mathrm{mbH}$, $1-12$.

Strauss, W. \& Howe, N., (1997) The fourth turning, New York. Broadway Books.

Troutman, C.M. \& Shanteau, J., (1976) Do consumers evaluate products by adding or averaging attribute information?. Journal of Consumer Research, 3, 101-106.

United Nations Economic Commission for Europe (UNECE), Working Group on Ageing (2009) Policy brief on Older Persons as Consumers, No 3, 1-12.

Van Eeden, E., (2013) Consumer Protection Law in South Africa, LexisNexis, South Africa.

Yoon, C., \& Cole, C.A., (2008) Aging and Consumer Behaviour in Handbook of Consumer Psychology (eds. Haugtvedt, Herr, and Kardes), Lawrence Erlbaum Associates. 247 - 270. 